AUDIT

\title{
Audit on flexible sigmoidoscopy for rectal bleeding in a district general hospital: are we over-loading the resources?
}

\author{
J Mathew, P Shankar, I M Aldean
}

Postgrad Med J 2004;80:38-40. doi: 10.1136/pgmi.2003.008284

See end of article for authors' affiliations .....................

Correspondence to: Mr John Mathew, 8 Fern House, Amberley Drive, Wythenshawe,

Manchester M23 2RW UK; mathewjohn9@ aol.com

Submitted 30 March 2003 Accepted 12 June 2003
Objective: Patients with rectal bleeding are being over investigated because of the fear of missing colorectal cancers. This study aimed to identify the percentage of patients $<\mathbf{4 5}$ years of age who undergo flexible sigmoidoscopy for rectal bleeding, and to assess and compare the incidence of colorectal cancers and polyps above and below this age.

Methods: Patients who underwent flexible sigmoidoscopy for rectal bleeding between 1 January 2000 and 31 December 2002 were reviewed. Patients were divided into two groups: group 1 consisted of patients aged $\geqslant 45$ years and group 2 patients $<45$ years. The histopathology of biopsy specimens taken was also studied.

Results: Altogether $18.9 \%$ of the patients who had flexible sigmoidoscopy for rectal bleeding were $<45$ years. The incidence of colorectal cancers in group 1 was 3.5\%; all these cases were confirmed on histopathology. Only one patient in group 2 was diagnosed with colorectal cancer on flexible sigmoidoscopy, but the histopathology disproved it. The incidence of polyps was $16.6 \%$ in group 1 and $7.9 \%$ in group 2. Following histopathology, the incidence of adenomatous polyps was $6.8 \%$ in group 1 and $2.1 \%$ in group 2. There was a significant difference between the two groups, with a $p$ value of $<0.0001$.

Conclusion: The incidence of colorectal cancers and adenomatous polyps in patients aged $<\mathbf{4 5}$ years with rectal bleeding is very low. A flexible sigmoidoscopy costs approximately $£ 330$. If new guidelines are implemented considering the age of the patient, considerable cost savings could be made, and the available resources could be appropriately used in groups with high incidences of colorectal cancers.
$\mathrm{T}$ he vast majority of patients referred to surgeons for investigation of rectal bleeding have benign anal disease or proctitis. ${ }^{1}$ Because of the fear of missing colonic cancers, patients are probably being over investigated. Full evaluation of the colon in all these patients imposes a considerable strain on the hospital resources and also exposes the patients to significant inconvenience and morbidity. The relative risk for colonic cancer in a 45 year old with no family history of colonic cancer is $1 \% .^{2}$ To utilise the available resources adequately, and to improve the diagnostic yield of colorectal cancers in patients with rectal bleeding, guidelines need to be implemented. At present there are no set guidelines stating the appropriate investigation in patients with rectal bleeding, taking into account the age and the associated symptoms. The aims of our study were to assess the number of patients undergoing flexible sigmoidoscopy for rectal bleeding below the age of 45 years and to assess and compare the incidence of colorectal cancers and polyps in patients above and below 45 years of age undergoing flexible sigmoidoscopy for rectal bleeding.

\section{METHODS}

Trafford General Hospital is a district general hospital serving a population of 300000 . Data for all patients who had flexible sigmoidoscopy between I January 2000 and 31 December 2002 were collected from the computer database of the endoscopy department. Exclusion criteria included all patients undergoing reassessment flexible sigmoidoscopy (for colonic polyps, colorectal cancers, inflammatory bowel disease, etc). After exclusion, patients who had flexible sigmoidoscopy for rectal bleeding were divided into two groups: group 1 (aged $\geqslant 45$ years) and group 2 (aged $<45$ years). Histology reports for the patients who had biopsies taken for suspected cancers and polyps during the flexible sigmoidoscopy were identified from the computer database of the pathology department. Statistical difference between the two groups was calculated using the $\chi^{2}$ test.

\section{RESULTS}

A total of 2614 patients had flexible sigmoidoscopy during this three year period; 232 patients had reassessment flexible sigmoidoscopy, and thus after exclusion there were 2382 patients. Out of these, 1275 patients (53.5\%) had flexible sigmidoscopy for rectal bleeding as shown in table 1 . The male to female ratio in group 1 (patients aged 45 years and above who had flexible sigmoidoscopy for rectal bleeding) was $1.4: 1$, and in group 2 (patients less than 45 years of age who had flexible sigmoidoscopy for rectal bleeding) it was $1.3: 1$. Group 1 consisted of 1033 patients $(81.0 \%)$; 36 patients in this group where found to have colonic cancers, and 171 patients had polyps diagnosed on flexible sigmoidoscopy (table 2). Histopathology confirmed all 36 cancers diagnosed on flexible sigmoidoscopy, and 70 out of 171 patients were found to have adenomatous polyps (table 3 ). Group 2 includes all patients below 45 years of age who had flexible sigmoidoscopy for rectal bleeding and consisted of 242 patients (19.0\%). In this group 19 patients were identified as having colonic polyps on flexible sigmoidoscopy. Following histopathology only five patients $(2.1 \%)$ were found to have adenomatous polyps. Although one patient in this group was diagnosed with colonic cancer on flexible sigmoidoscopy, the histopathology showed a hyperplastic polyp with no evidence of cancer. 


\begin{tabular}{|c|c|}
\hline $\begin{array}{l}\text { Indications for flexible } \\
\text { sigmoidoscopy }\end{array}$ & $\begin{array}{l}\text { No }(\%) \text { of patients and } \\
\text { percentage }\end{array}$ \\
\hline $\begin{array}{l}\text { Rectal bleeding } \\
\text { Alteration in bowel habit } \\
\text { Abdominal pain } \\
\text { Other (weight loss, mass per } \\
\text { abdomen, anaemia, melaena, } \\
\text { incontinence, mucus discharge, } \\
\text { perianal discomfort }\end{array}$ & $\begin{array}{l}1275(53.5) \\
474(19.9) \\
192(8.1) \\
441(18.5)\end{array}$ \\
\hline
\end{tabular}

The statistical difference between the two groups was calculated using a $\chi^{2}$ test and found to be significant with a $\mathrm{p}$ value of less than 0.0001 .

\section{Cost implications}

A flexible sigmoidoscopy in our hospital costs approximately $£ 330$ per person.

\section{DISCUSSION}

Because of the fear of missing colonic cancers, it is possible that patients with benign perianal diseases are being over investigated. The concern for most patients with rectal bleeding is whether there is an underlying neoplasia. The diagnostic yields of colonic cancers in such patients are very low. ${ }^{3}$ During the life of an adult, rectal bleeding has a reported incidence of between $16 \%$ and $33 \% .^{1-4}$ Colonoscopy would be a safe option, but if all of these patients were to undergo colonoscopy, then the NHS would definitely have difficulty coping. Flexible sigmoidoscopy diagnoses the majority of significant pathologies in patients with rectal bleeding, ${ }^{5-7}$ and thus it would be a more sensible alternative. From the patient's description of the bleeding, it may not be possible to localise the site to a benign lesion originating from the anus. ${ }^{8}{ }^{9}$ There is a lack of agreement as to the need for and the type of further investigation. In patients with rectal bleeding, age is the most significant variable in predicting colorectal cancers and polyps. Change in bowel habit is second only to age in predicting colorectal cancers and polyps. ${ }^{10}$ In a 10 year prospective study of 201 individuals at the Veterans Affairs Medical Centre in California with rectal bleeding, none of the patients below the age of 50 years had cancer. ${ }^{11}$ Similarly, in the Netherlands, a study of 290 consecutive patients with rectal bleeding found that no patients aged less than 50 years had colorectal cancer. ${ }^{10}$

The relative risk of bowel cancer in a 45 year old with no family history is $1 \%{ }^{8}$ In our study, none of the patients with rectal bleeding below the age of 45 years proved to have cancer following histopathology. Although 7.9\% (19 out of 242 ) of the patients below the age of 45 years were diagnosed with colorectal polyps on flexible sigmoidoscopy, only $2.1 \%$ (five out of 242) had adenomatous polyps on histopathology. This is considerably lower than in patients aged 45 years and above. A significant percentage of the patients who had flexible sigmoidoscopy for rectal bleeding were below the age of 45 years ( 242 out of $1275 ; 19.0 \%$ ). In this group, $36.8 \%$ of patients ( 89 out of 242) were reported to have haemarrhoids, and a large number of patients were reported to be normal on flexible sigmoidoscopy $(44.6 \%$; $=108)$, which could partly be due to the under-reporting of benign anal disease with a view to the patients being reassessed in the clinic for their treatment.

Another possible way of reducing unnecessary investigations is review of the request cards by the consultant before endoscopy. This would mean extra work, time, and
Table 2 Diagnoses of patients in group 1 (patients aged $\geqslant 45$ years) and group 2 (patients aged $<45$ years); values are number (\%)

\begin{tabular}{|c|c|c|}
\hline Diagnosis & $\begin{array}{l}\text { Group 1 } \\
(n=1033)\end{array}$ & $\begin{array}{l}\text { Group 2 } \\
\text { (n }=242)\end{array}$ \\
\hline $\begin{array}{l}\text { Nothing abnormal } \\
\text { detected }\end{array}$ & $214(20.7)$ & $108(44.6)$ \\
\hline Haemorrhoids & $301(29.1)$ & $89(36.8)$ \\
\hline Diverticular disease & $218(21.1)$ & $9(3.7)$ \\
\hline Colitis & $49(4.7)$ & $6(2.5)$ \\
\hline Polyps & $171(16.6)$ & $19(7.9)$ \\
\hline Carcinoma & $36(3.5)$ & $1(0.4)$ \\
\hline $\begin{array}{l}\text { Other (melanosis coli, } \\
\text { anal polyp, radiation } \\
\text { proctitis, submucus } \\
\text { lipoma, solitary rectal } \\
\text { ulcer, anal fissure) }\end{array}$ & $44(4.3)$ & $10(4.1)$ \\
\hline
\end{tabular}

Table 3 Numbers and percentages of cancers and adenomatous polyps on histopathology in patients in group 1 (patients aged $\geqslant 45$ years) and group 2 (patients aged $<\mathbf{4 5}$ years); values are number $(\%)$

\begin{tabular}{lll}
\hline Histopathology & Group 1 (n $=$ 1033) & Group 2 (n = 242) \\
\hline Carcinomas & $36(3.5)$ & 0 \\
$\begin{array}{l}\text { Adenomatous } \\
\text { polyps }\end{array}$ & $70(6.8)$ & $5(2.1)$ \\
\hline
\end{tabular}

responsibility on the part of the consultant. In our study the most likely source of rectal bleeding in patients aged less than 45 years was benign perianal disease, and the incidence of cancers and adenomatous polyps in this group was seen to be very low. Approximately one fifth of the patients who had flexible sigmoidoscopy for rectal bleeding were below the age of 45 years. A flexible sigmoidoscopy in our hospital costs approximately £330, and considerable money could be saved if patients were appropriately selected. In our view, patients aged less than 45 years with rectal bleeding from an identifiable perianal source and no added risk factors (family history of colorectal cancer or inflammatory bowel disease, alteration in bowel habit) need not undergo flexible sigmoidosopy in the first instance. Patients should be assessed initially with rigid sigmoidoscopy and proctoscopy, and identifiable perianal disease should be treated. If the bleeding persists even after the treatment of perianal disease and no identifiable cause is found, flexible sigmoidoscopy is advised. Age, although a significant factor in predicting colorectal cancers, should not be the only criterion when considering flexible sigmoidoscopy in patients with rectal bleeding. If these patients have additional risk factors, there is strong clinical suspicion of colorectal cancer or persistent symptoms are present, a flexible sigmoidoscopy and/or even a full colonic evaluation using Barium enema or colonoscopy should be considered.

\section{CONCLUSION}

Approximately one fifth of the patients who had flexible sigmoidoscopy for rectal bleeding were below the age of 45 years. The actual number of patients diagnosed with colorectal cancers or adenomatous polyps in this age group was seen to be very low. Hence, in order to utilise the available resources adequately, new guidelines need to be implemented taking into account age as an important criterion when considering flexible sigmoidoscopy for rectal bleeding. 


\section{Authors' affiliations}

J Mathew, P Shankar, I M Aldean, Department of Surgery, Trafford

General Hospital, Manchester, UK

\section{REFERENCES}

1 Tally NJ, Jones M. Self-reported rectal bleeding in a United States community. Prevalence, risk factors, and health care seeking. Am J Gastroenterol 1998:93:2179-83.

2 NHS Executive. The management of colorectal cancer. Effective Health Care 1997;3:1-11.

3 Douek M, Wickramasinghe M, Clifton MA. Does isolated rectal bleeding suggest colorectal cancer? Lancet 1999:354:393.

4 Sladden MJ, Thomson AN. How do general practitioners manage rectal bleeding? Aust Fam Physician 1998;27:78-82.

5 Van Rosendaal GM, Sutherland LR, Verhoef MJ, et al. Defining the role of fiberoptic sigmoidoscopy in the investigation of patients presenting with bright red rectal bleeding. Am J Gastroenterol 2000;95: 1184-7.

6 Fine KD, Nelson AF, Ellington RT, et al. Comparison of the color of the fecal bleed with the anatomical location of bright red blood per rectum. Am J Gastroenterol 1999:94:3202-10.

7 Church JM. Analysis of the colonoscopic findings in patients with rectal bleeding according to the pattern of their presenting symptom. Dis Colon Rectum 1991;34:391-5.

8 NHS Executive. Guidance on commissioning cancer services. Improving outcomes in colorectal cancers. The research evidence. London: Department of Health, 1997

9 National Health and Medical Research Council. Guidelines for the prevention, early detection and management of colorectal cancer (CRC). Canberra: Commonwealth of Australia, 1999.

10 Fitjen G, Starmans R, Muris J, et al. Predictive value of signs and symptoms of colorectal cancer in patients with rectal bleeding in general practice. Fam Practice 1995; 12:279-86.

11 Helfand M, Marton K, Zimmer-Gembeck M, et al. History of visible rectal bleeding in a primary care population. JAMA 1997;277:44-8.

\section{IMAGES IN MEDICINE}

\section{Sphenoidal sinus mucocoele presenting as mono-ocular painless loss of vision}

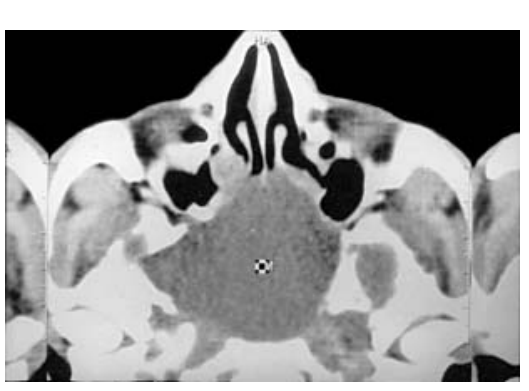

Figure 1 Computed tomogram of the paranasal sinus showing sphenoidal sinus mucocoele with a defect of the lateral wall.

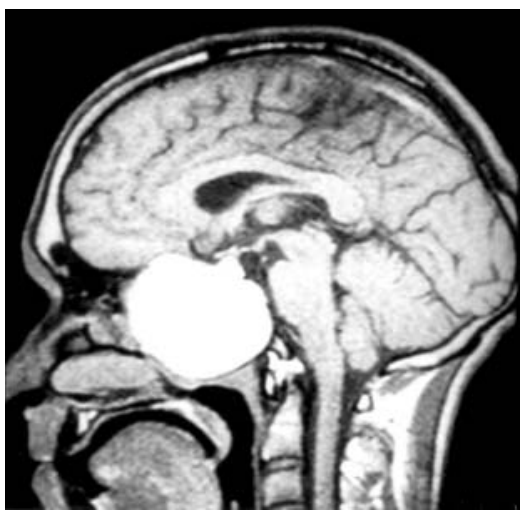

Figure 2 MRI of the brain showing mucocoele in the sphenoid sinus.
A 22 year old man presented with acute onset of loss of vision in the right eye of six hours' duration. There were no associated complaints of pain or redness of eye. There was no associated convulsion or alteration in sensorium. He complained of a mild headache over the past two days. On examination the perception of light in the right eye was absent. Light and accommodation reflex testing revealed a right afferent abnormality. Funduscopy showed blurred disc margins and pallor of the right optic disc. Eye movements were normal and painless. There was no other focal neurological deficit.

A computed tomogram of the brain and paranasal sinus (fig 1) revealed a large mucocoele in the right sphenoidal sinus, with a defect in the lateral wall of the sinus. Optic nerve imaging with gadolinium enhanced magnetic resonance imaging (MRI, fig 2) confirmed the findings and did not reveal any optic nerve signal abnormality to suggest demyelination.

An emergency sinoscopy was performed and drainage of the mucocoele was done. The patient's vision improved within one day postoperatively and there was no recurrence of the symptoms at follow up. Our case report highlights an unusual cause of acute painless monoocular vision loss. Acute blindness as a presentation of sphenoidal sinus mucocoele occurs very rarely. The common presentation of sphenoidal sinus mucocoele is diplopia, proptosis, Horner's syndrome, multiple cranial palsies, and panhypopitutarism.

U Sundar Lokmanya Tilak Medical College and General Hospital, Mumbai, India A L Sharma LTMG Hospital, Sion, Mumbai, India; drandy2003@yahoo.co.in M E Yeolekar Lokmanya Tilak Medical College and General Hospital, Mumbai, India

V Pahuja LTMG Hospital, Sion, Mumbai, India 